\title{
Eftective Ionization Coefficients, Electron Drift Velocities, and Limiting Breakdown Fields for Gas Mixtures of Possible Interest to Particle Detectors ${ }^{\mathrm{I}}$
}

\author{
P. G. Datskos, L. G. Christophorou, and J. G. Carter \\ Atomic, Molecular, and High Voltage Physics Group \\ Health and Safety Research Division \\ Oak Ridge National Laboratory \\ Oak Ridge, Tennessee 37831
}

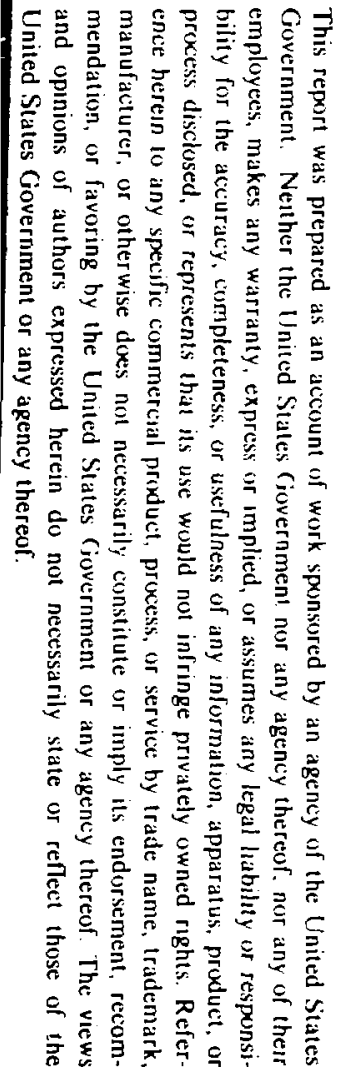

\author{
and \\ Department of Physics. The University of Tennessee \\ Knoxville, Tennessee 37996
}

\begin{abstract}
We have measured the gas-density, $\mathrm{N}$, normalized effective ionization coefficient, $\bar{\alpha} / \mathrm{N}$, and the electron drift velocity, $w$, as a function of the density-reduced electric fiejd, $\mathrm{E} / \mathrm{N}$, and obtained the limiting, $(E / N)_{1 \mathrm{im}}$, value of $E / N$ for the unitary gases $\mathrm{Ar}, \mathrm{CO}_{2}$, and $\mathrm{CF}_{4}$, the binary gas mixtures $\mathrm{CO}_{2}: \mathrm{Ar}(20: 80), \mathrm{CO}_{2}: \mathrm{CH}_{4}(20: 80)$, and $\mathrm{CF}_{4}: \mathrm{Ar}$ (20:80), and the ternary gas mixtures $\mathrm{CO}_{2}: \mathrm{CF}_{4}: \mathrm{Ar}(10: 10: 80)$ and $\mathrm{H}_{2} \mathrm{O}: \mathrm{CF}_{4}: \mathrm{Ar}$ (2:18:80). Addition of the strongly electron thermalizing gas $\mathrm{CO}_{2}$ or $\mathrm{H}_{2} \mathrm{O}$ to the binary mixture $\mathrm{CF}_{4}: \mathrm{Ar}$ (i) "cools" the mixture (i.e., lowers the electron energies), (ii) has only a small effect on the magnitude of $w(E / N)$ in the $E / N$ range employed in the particle detectors, and (iii) increases $\bar{\alpha} / \mathrm{N}$ for $E / N \geq 50 \times 10^{-17} \mathrm{~V} \mathrm{~cm}$. The increase in $\bar{\alpha} / \mathrm{N}$, even though the electron energies are lower in the ternary mixture, is due to the Penning ionization of $\mathrm{CO}_{2}\left(\right.$ or $\mathrm{H}_{2} \mathrm{O}$ ) in collisions with excited Ar atoms. The ternary mixtures -- being fast, cool, and efficient -- have potential for advanre $\mathbb{d}$ gas-filled particle detectors such as those for the SCC muon chambers.
\end{abstract}

${ }^{1}$ Research Sponsored by the Office of Heaith and Environmental Research, U. S. Department of Energy, under Contract No. DEAC05-84OR21400 with Martin Marietta Energy Systems. Inc.

1991 CEIDP Conference Récord

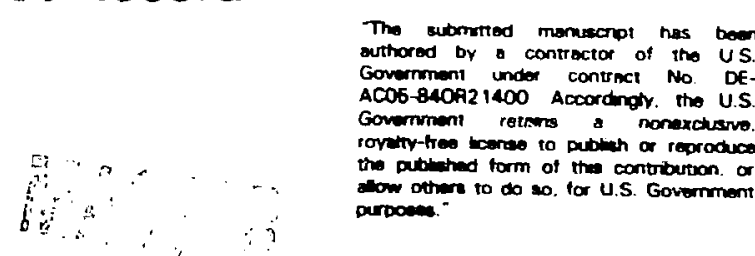




\section{INTRODUCTTON}

Considerable efforts have recently been made to explore and develop appropriate gas mixtures for use in particle detectors in general and in the Superconducting Super Collider (SCC) muon detectors in particular [1-4]. Gaseous media for precise particle detectors must possess good ctemical properties (e.g., low flammability and toxicity; be nonexplosive), high electron drift velocity, w, ("fast" gas), high gain ("efficient" gas), low electron diffusion ("cool" gas), and high corona inception and breakdown voltages; they also must be nonelectron attaching.

A measure of the efficiency of the detector gas mixture is the magnitude of the gas-density normalized effective ionization coefficient $\bar{\alpha} / \mathbb{N}$. We define $\bar{\alpha} / \mathbb{N}$ as the difference between the gas-density normalized ionization coefficient $\alpha / N$ and the gas-density normalized electron attachment coefficient $\eta / N$. Also, from the values of the $(E / N)_{\text {lim }}$ we can determine which gas mixtures possess better breakdown strengths.

In this paper we report our measurements on $w(E / N), \bar{\alpha} / N(E / N)$ and $(E / N)_{\text {lim }}$ for various unitary, binary, and ternary gas mixtures of possible interest to SSC muon detectors.

\section{EXPERIMENTAL TECHNIQUE}

The technique used has been described earlier [4]. The experimental set up is shown in Fig.1. The cell used consists of six-way $10.2 \mathrm{~cm}$ wide stainless steel cube with a sapphire window to allow a laser beam to enter the cell. The two parallel stainless steel electrodes were circular disks of $3.8 \mathrm{~cm}$ diameter and were held at a distance of $1.01 \mathrm{~cm}$. The photon strike the cathode through a hole $(\sim 0.1 \mathrm{~cm}$ diameter $)$ in the anode electrode; a converging lens was used to pass the laser light through the hole. The induced signal due to the motion of the photoelectrons in the drift gap was detected and recorded with a Tektronix $7912 \mathrm{AD}$ digitizer through a $50 \Omega$ resistor to ground; this signal is proportional to the induced electron current in the gap. From the recorded electron current u aveforms we determined the electron drift velocity and the effective ionization coefficient as a function of $\mathrm{E} / \mathrm{N}$.

The gases used $\operatorname{Ar}(99.999 \%), \mathrm{CO}_{2}(99.995 \%), \mathrm{CF}_{4}(99.9 \%)$ and $\mathrm{CH}_{4}(99.99 \%)$ were obtained from Matheson Gas Products and the $\mathrm{H}_{2} \mathrm{O}$ (99.9\%) was purchased from Aldrich Chemical Company. s.ll the samples were subjected to several vacuum distillation cycles prio" ${ }^{\prime}$, an' measurements in order to remove air from the samples. Fit the measurements were made at $\mathrm{T}-300 \mathrm{~K}$ and the total gas number density was varied from $6.48 \times 10^{16}$ to $2.43 \times 10^{19}$ molecules $\mathrm{cm}^{-3}$. 


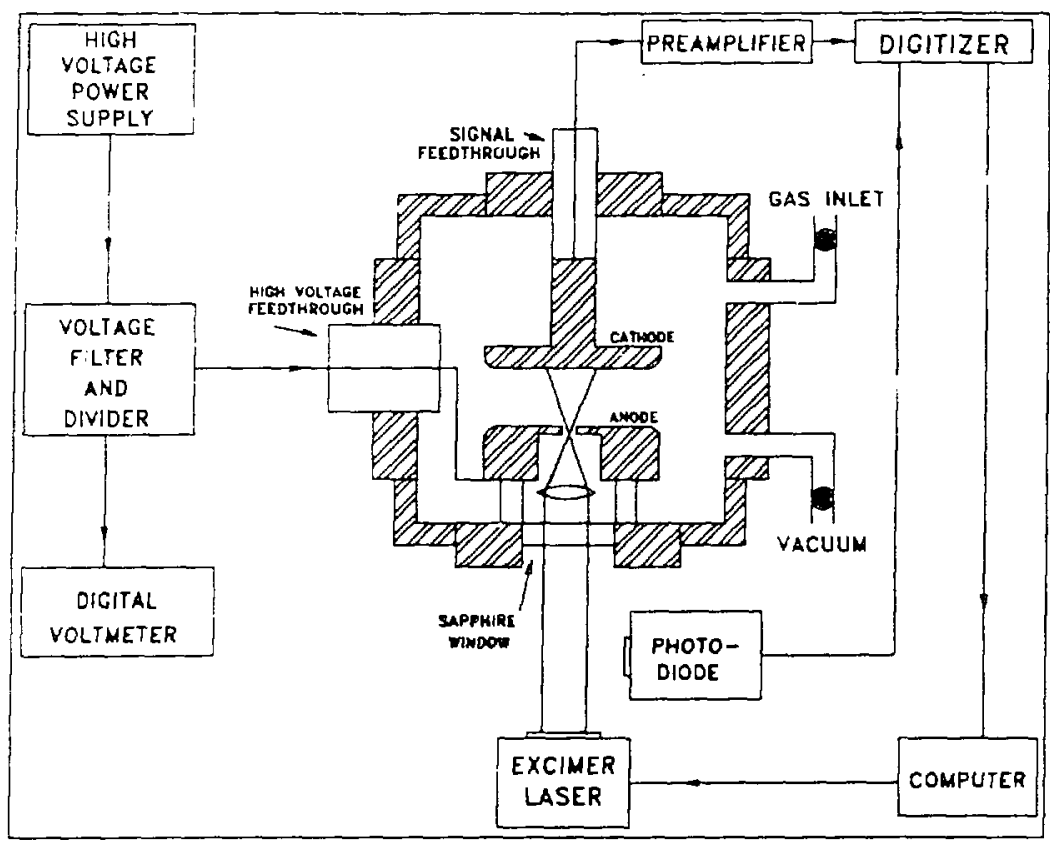

Fig. 1. Schematic diagram of the experimental set up.

\section{RESULTS}

\section{A. Unitary Gases}

In Fig. 2 we present our measurements of $\bar{\alpha} / \mathrm{N}(\mathrm{E} / \mathrm{N})$ for $\mathrm{Ar}, \mathrm{CO}_{2}$ and $\mathrm{CF}_{4}$. The agreement between the measured $\bar{\alpha} / \mathrm{N}(\mathrm{E} / \mathrm{N})$ for $\mathrm{CO}_{2}$ and the earlier reported experimental values [5] is good while the reported calculated results [6] are higher than both the present and earlier experimental results. The $\bar{\alpha} / \mathrm{N}(\mathrm{E} / \mathrm{N})$ for $\mathrm{CF}_{4}$ are in excellent agreement with previous measurements [7]. The $\bar{\alpha} / \mathrm{N}(\mathrm{E} / \mathrm{N})$ for $\mathrm{Ar}$ becomes positive at $\mathrm{E} / \mathrm{N}-25 \times 10^{-17} \mathrm{~V} \mathrm{~cm}^{2}$ and rapidly exceeds that of either $\mathrm{CO}_{2}$ or $\mathrm{CF}_{4}$. This reflects the fact that for a fixed $\mathrm{E} / \mathrm{N}$ the mean electron energies in Ar are much higher than for the other two gases. The electrons are slowed-down more efficiently in $\mathrm{CO}_{2}$ and $\mathrm{CF}_{4}$ principally because of the low-lying negative ion states for $\mathrm{CO}_{2}$ and because of both the low vibrational thresholds and negative ion states for $\mathrm{CF}_{4}$.

In Fig. 3 are presented our measurements of $w(E / N)$ for $A r$, $\mathrm{CO}_{2}$, and $\mathrm{CF}_{4}$. For $\mathrm{CO}_{2}$ the measured $\mathrm{w}(\mathrm{E} / \mathrm{N})$ are in excellent agreement with data found in the literature $[8-10]$ for $E / N<200 \times 10^{-17} \mathrm{~V} \mathrm{~cm}^{2}$

\section{CEIDP Conference Record}




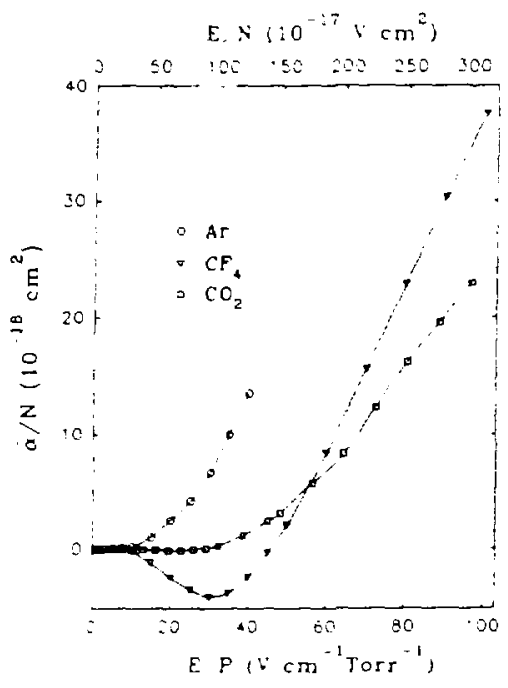

Fig. 2. Measured $\bar{\alpha} / \mathrm{N}$ vs $E / N$ (or $\mathrm{E} / \mathrm{P}$ ) for $\mathrm{Ar}, \mathrm{CF}_{4}$, and $\mathrm{CO}_{2}$.

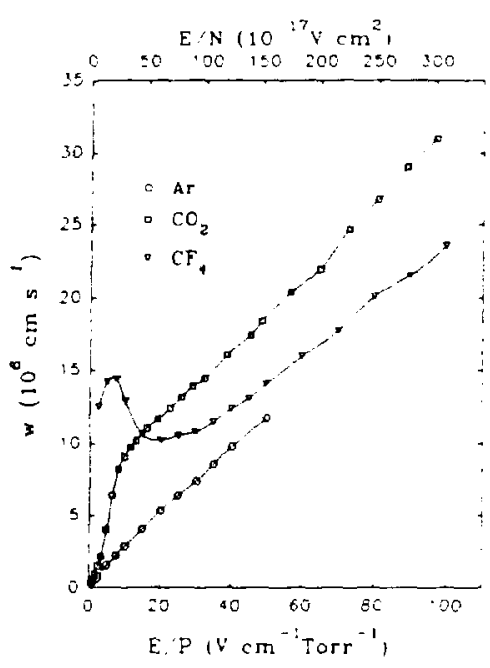

Fig. 3. Measured w vs $\mathrm{E} / \mathrm{N}$ (or $\mathrm{E} / \mathrm{P}$ ) for $\mathrm{Ar}, \mathrm{CF}_{4}$, and $\mathrm{CO}_{2}$.

while for higher $E / N$ values the measured $w(E / N)$ are higher than those reported [10]. The measured $w(E / N)$ for $\mathrm{CF}_{4}$ compare well with earlier work [11]. Figure 3 shows the superior properties of $\mathrm{CF}_{4}$ in terms of electron drift $[3,4,11-13]$. In the $\mathrm{E} / \mathrm{N}$ range in which the particle detector would normally operate $\left(\mathrm{ENN}<10 \times 10^{-17} \mathrm{~V} \mathrm{~cm}^{2}\right) \mathrm{CF}_{4}$ possesses the highest electron drift velocity from all the three systems studied.

\section{B. Binary Gas Mixtures}

In Fig. 4 we summarize our measurements of $\bar{\alpha} / \mathrm{N}(\mathrm{E} / \mathrm{N})$ for the binary mixtures $\mathrm{CF}_{4}: \mathrm{Ar}(20: 80), \mathrm{CO}_{2}: \mathrm{As}(20: 80)$ and $\mathrm{CO}_{2}: \mathrm{CH}_{4}(20: 80)$. At $\mathrm{E} / \mathrm{N}>150 \times 10^{-17} \mathrm{~V} \mathrm{~cm}^{2}$, the $\mathrm{CF}_{4}$ :Ar mixture exhibits the highest $\bar{\alpha} / \mathrm{N}$ values, but $\bar{\alpha} / \mathrm{N}$ becomes negative below $-72 \times 10^{-17} \mathrm{~V} \mathrm{~cm}^{2}$ attaining its lowest value at $-50 \times 10^{-17} \mathrm{~V} \mathrm{~cm}$. This indicates that in the $E / N$ range from $\sim 15 \times 10^{-17}$ to $\sim 72 \times 10^{-17} \mathrm{~V} \mathrm{~cm}^{2}$ electron attachment exceeds ionization. The $\mathrm{CO}_{2}: \mathrm{Ar}$ mixture has a somewhat lower $\bar{\alpha} / \mathrm{N}$ than the $C_{F_{4}}$ :Ar binary mixture for $\mathrm{E} / \mathrm{N}>150 \times 10^{-17} \mathrm{~V} \mathrm{~cm}^{2}$. However, for the $\mathrm{CO}_{2}: \mathrm{Ar}$ gas mixture $\bar{\alpha} \mathrm{N}$ remains always positive. The third binary gas mixture $\mathrm{CO}_{2}: \mathrm{CH}_{4}$ exhibits the lowest $\bar{\alpha} / \mathrm{N}(\mathrm{E} / \mathrm{N})$ values of the three binary systems studied for $\mathrm{E} / \mathrm{N}>72 \times 10^{-17} \mathrm{~V} \mathrm{~cm}$. Below this $\mathrm{E} / \mathrm{N}$

\section{CEIDP Conference Record}




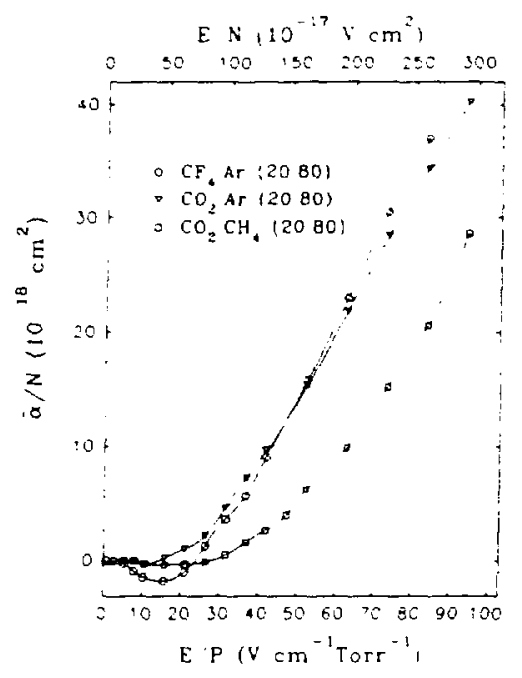

Fig. 4. Measured $\bar{\alpha} / \mathrm{N}$ vs $E / N$ for $\mathrm{CF}_{4}: \mathrm{Ar}, \mathrm{CO}_{2}: \mathrm{Ar} \mathrm{CO}_{2}: \mathrm{CH}_{4}$ binary gas mixtures.

value, the $\bar{\alpha} / \mathrm{N}(\mathrm{E} / \mathrm{N})$ for $\mathrm{CO}_{2}: \mathrm{CH}_{4}$ is smaller than that of $\mathrm{CO}_{2}: \mathrm{Ar}$, but larger than the $\bar{\alpha} / \mathrm{N}$ for $\mathrm{CF}_{4}: A r$. In Figures 5 and 6 we summarize our measurements on $w(E / N)$ for the binary mixtures we studied. In Fig. 5 we compare the $w$ for $\mathrm{CF}_{4}: \mathrm{Ar}$ (20:80) and $\mathrm{CO}_{2}: \mathrm{CH}_{4}(20: 80)$ and in Fig. 6 that for $\mathrm{CF}_{4}$ :Ar (20:80) and $\mathrm{CO}_{2}: \mathrm{Ar}(20: 80)$.

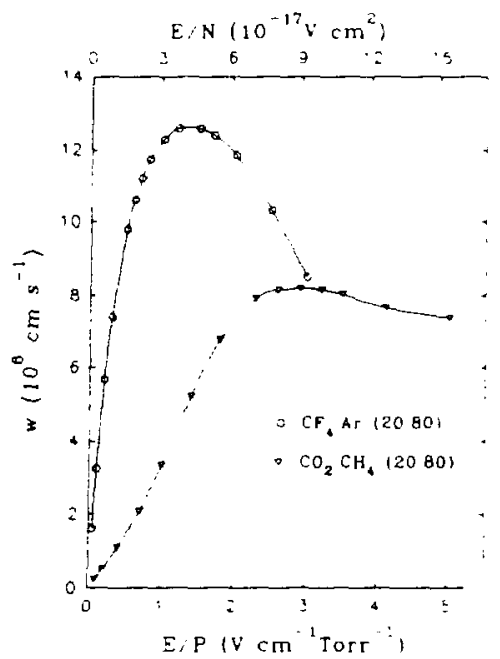

Fig. 5. Measured $w$ vs $E / N$ (or E/P) for $\mathrm{CF}_{4}: \mathrm{Ar}(20: 80)$ and $\mathrm{CO}_{2}: \mathrm{CH}_{4}$ (20:80) gas mixtures.

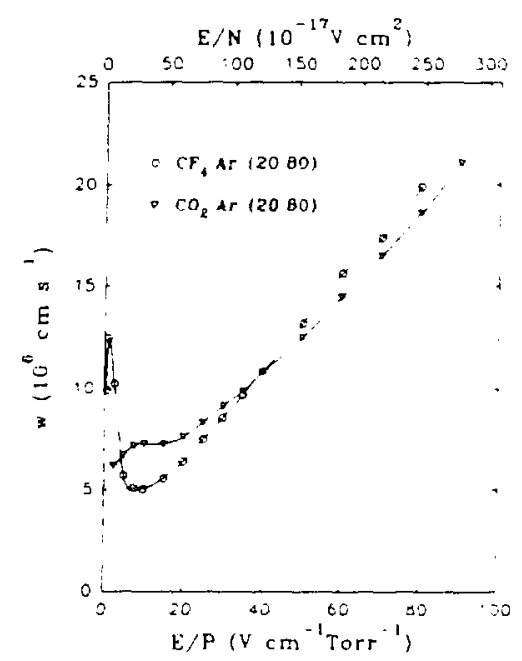

Fig. 6. Measured $w$ vs $E / N$ (or $E / P$ ) for $\mathrm{CF}_{4}: \mathrm{Ar} \quad(20: 80)$ and $\mathrm{CO}_{2}: \mathrm{Ar}$ (20:80) gas mixtures. 


\section{Ternary Gas Mixtures}

Because of the favorable transport properties of the $\mathrm{CF}_{4}$ : $\mathrm{Ar}$ mixtures we selected the $\mathrm{CF}_{4}: \mathrm{Ar}(20: 80)$ gas mixture for possible enhancement of its electron yield. This we attempted by addition of a third additive which also shifts the electron energies to lower values (making it "cooler"). We used two known good electron thermalizing molecules $[13,14] \mathrm{CO}_{2}$ and $\mathrm{H}_{2} \mathrm{O}$. We measured $\bar{\alpha} / \mathrm{N}$ and $\mathrm{w}$ as a function of $\mathrm{E} / \mathrm{N}$ for the ternary mixtures $\mathrm{CO}_{2}: \mathrm{CF}_{4}: \mathrm{Ar}(10: 10: 80)$ and $\mathrm{H}_{2} \mathrm{O}: \mathrm{CF}_{4}: \mathrm{Ar}$ $(2: 18: 80)$. The measured $\vec{\alpha} / \mathrm{N}(\mathrm{E} / \mathrm{N})$ and $w(E / N)$ are plotted in Figs. 7 and 8 , respectively along with the $\bar{\alpha} / \mathrm{N}(\mathrm{E} / \mathrm{N})$ and $w(E / N)$ for $\mathrm{CF}_{4}: \operatorname{Ar}(20: 80)$ for comparison. We found that $\bar{\alpha} / \mathrm{N}(\mathrm{E} / \mathrm{N})$ for $\mathrm{CO}_{2}: \mathrm{CF}_{4}: \mathrm{Ar}(10: 10: 80)$ is always $z 0$ over the entire $E / N$ range studied and that it is also somewhat higher than that for $\mathrm{CF}_{4}: \mathrm{Ar}(20: 80)$ in spite of the fact that the electron energies shift towards lower values for a given $E / N$ value [3]. For the $\mathrm{H}_{2} \mathrm{O}: \mathrm{CF}_{4}: \operatorname{Ar}(2: 18: 80), \bar{\alpha} / \mathrm{N}(\mathrm{E} / \mathrm{N})$ becomes negative for values of $\mathrm{E} / \mathrm{N}$ below $<73 \times 10^{-17} \mathrm{~V} \mathrm{\textrm {cm } ^ { 2 }}$. However, when $\mathrm{E} / \mathrm{N} \geq 100 \mathrm{x}$ $10^{-17} \mathrm{~V} \mathrm{~cm}{ }^{2}, \bar{\alpha} / \mathrm{N}(\mathrm{E} / \mathrm{N})$ attains values which are larger than those in either $\mathrm{CF}_{4}: \operatorname{Ar}(20: 80)$ or $\mathrm{CO}_{2}: \mathrm{CF}_{4}: \operatorname{Ar}(10: 10: 80)$; this is due to the Penning ionization of $\mathrm{H}_{2} \mathrm{O}$ molecules by the excited $\mathrm{Ar}^{*}$ atoms.

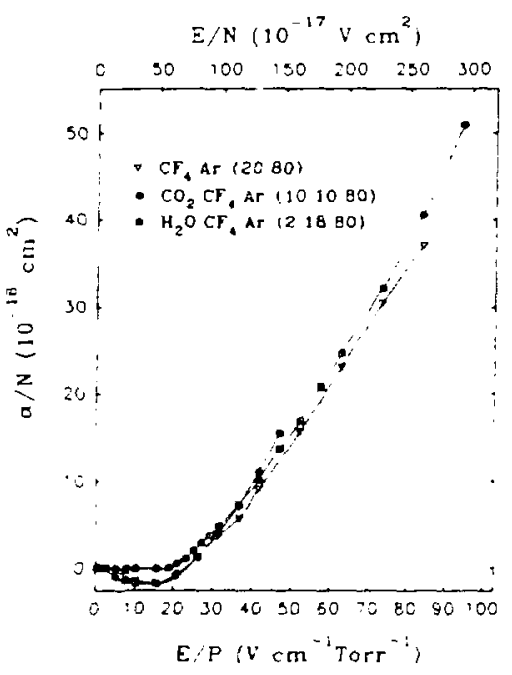

Fig. 7. Measured $\bar{\alpha} \mathrm{N}$ vs $\mathrm{E} / \mathrm{N}$ (or $\mathrm{E} / \mathrm{P})$ for $\mathrm{CF}_{4}: \mathrm{Ar}(20: 80), \mathrm{CO}_{2}: \mathrm{CF}_{4}: \mathrm{Ar}$ $(10: 10: 80)$ and $\mathrm{H}_{2} \mathrm{O}: \mathrm{CF}_{4}: \mathrm{Ar}(2: 18: 80)$ gas mixtures.

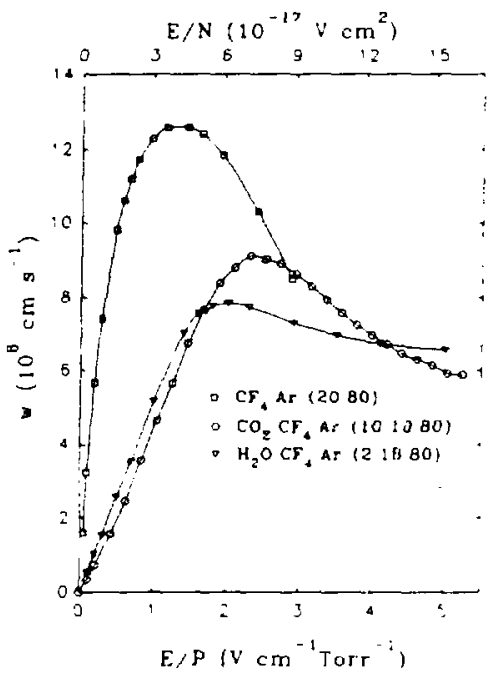

Fig. 8. Measured w vs $E / N$ (or $E / P$ ) for $\mathrm{CF}_{4}: \mathrm{Ar} \quad(20: 80), \mathrm{CO}_{2}: \mathrm{CF}_{4}: \mathrm{Ar}$ (10:10:80) and $\mathrm{H}_{2} \mathrm{O}: \mathrm{CF}_{4}: \mathrm{AI}_{\mathrm{I}}$ (2:18:80) gas mixtures. 
D. Limiting Electric Field Strengths

The limiting electric field strength, $(E / N)_{\text {iim }}$, of a gas is defined $[7,14]$ as the maximum $E / N$ value for which $\bar{\alpha} / N I=(\alpha / N-\eta / N)]$ is still $\leq 0$. Under certain conditions (e.g., absence of significant secondary electron loss or gain processes such as secondary ionization, electron detachment, etc.) $(\mathrm{E} / \mathrm{N})_{\text {lim }}$ can be identified with the uniform breakdown field strength of the gaseous medium. We determined approximate values of $(E / N)_{\text {lim }}$ for the gas mixtures we studied. These are summarized in Table I along with earlier experimental values for the unitary gases.

TABLE 1. Approximate Values of the Electric Field Strength, $(\mathrm{E} / \mathrm{N})_{\text {lim. }}$

\begin{tabular}{lcc}
\hline Gas/Mixture & \multicolumn{2}{c}{$(\mathrm{E} / \mathrm{N})_{\text {lim }}\left(10^{-17} \mathrm{~V} \mathrm{~cm}^{2}\right)$} \\
\hline $\mathrm{Ar}$ & 25 & Previous values \\
$\mathrm{CF}_{4}$ & 142 & $25.2^{[|3|}$ \\
$\mathrm{CO}_{2}$ & 93 & $140^{[7]}, 143^{[15],[16]}$ \\
$\mathrm{CF}_{4}: \mathrm{Ar}(20: 80)$ & 72 & $108^{[17]}, 87^{[5]}$ \\
$\mathrm{CO}_{2}: \mathrm{Ar}(20: 80)$ & 42 & \\
$\mathrm{CO}_{2}: \mathrm{CH}_{4}(20: 80)$ & 85 & \\
$\mathrm{CO}_{2}: \mathrm{CF}_{4}: \mathrm{Ar}(10: 10: 80)$ & 55 & \\
$\mathrm{H}_{2} \mathrm{O}: \mathrm{CF}_{4}: \mathrm{Ar}(2: 18: 80)$ & 73 & \\
\hline
\end{tabular}

\section{CONCLUSIONS}

The results presented in this paper show that it is possible to develop multicomponent gas mixtures that are both fast $\left(w \sim 10^{7} \mathrm{~cm} \mathrm{~s}^{-1}\right)$ and $\mathrm{cool}[\langle\varepsilon\rangle<1 \mathrm{eV}$ at convenient operating $\mathrm{E} / \mathrm{N}$ values (less than

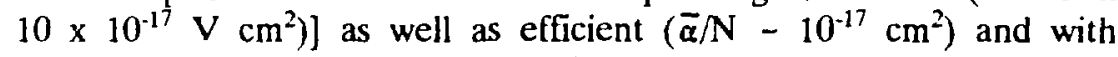
reasonably high $(\mathrm{E} / \mathrm{N})_{\text {lim }}$ values. While a number of binary gas mixtures appear to be suitable for muon and other high-energy particle detectors, ternary gas mixtures such as $\mathrm{CO}_{2}: \mathrm{CF}_{4}: \mathrm{Ar}$ or $\mathrm{H}_{2} \mathrm{O}: \mathrm{CF}_{4}: \mathrm{Ar}$ in approximate ratios of 10:10:80 and 2:18:80, respectively, seem to be promising based on the present measurements of their electron drift velocities, effective ionization coefficients, and $(\mathrm{E} / \mathrm{N})_{\text {lim }}$ and mean electron energies reported earlier [3]. 
REFERENCES

[1] U. Becker, M. Carrel. M. Chci, M. White, C. H. YE, K. YEE, J. Fehlmann, and P. G. Seiler, Nucl. Instr. Meth. 214, 525 (1983).

[2] R. Donaldson and M. G. D. Gilchriese (Eds.), in Experiments, Detectors, and Experimental Areas for the Supercollider, World Scientific Publishing Company, Singapore (1988).

[3] L. G. Christophorou, P. G. Datskos, and J. G. Carter, Nucl. Instr. Meth. Phys. Res. (in Press).

[4] P. G. Datskos, J. G. Carter, and L. G. Christophorou, J. Chem. Phys. (submitted).

[5] M. S. Bhalla and T. D. Craggs, Proc. Phys. Soc. 76, 369 (1960).

[6] H. N. Kucukarpaci and J. Lucas, J. Phys. D 12, 2123 (1979).

[7] S. R Hunter, J. G. Carter, and L. G. Christophorou, J. Chem. Phys. 86, 693 (1987).

[8] M. T. Elford and G. N. Haddad, Austr. J. Phys., 33, 517 (1980).

[9] R. A. Sierra. H. L. Brooks. A. J. Sommever, S. R. Foltyn, and K. T. Nygaard, J. Phys. D 14, 1791 (1981).

[10] H. T. Saellee, J. Lucas, and T. W. Limbeek, IEE Solid State Electron. Dev. 1, 111 (1979).

[11] L. G. Christophorou, D. L. McCorkle, D. V. Maxey, and J. G. Carter, Nucl. Insir. Meth 163141 (1979).

[12] L. G. Christophorou, Atomic and Molecular Radiation Physics, Wiley, New York (1971).

[13] L. G. Christophorou and S. R. Hunter, in Electron Molecule Interactions and Their Applications, (Ed. L. G. Christophorou) Academic Press, New York (1984).

[14] L. G. Christophorou and L. A. Pinnaduwage, IEEE Trans. Elect. Insul. 25, 55 (1990).

[15] C. S. Lakshminarasimha, J. Lucas, and D. A. Price, Proc. Inst. Electr. Eng. 120, 1044 (1973).

[16] C. S. Lakshminarasimha, J. Lucas, and R. A. Snelson, Proc. Inst. Electr. Eng. 122, 1162 (1975).

[17] L. G. Christophorou, D. R. James, and R. Y. Pai, in Applied Atomic Collision Physics (Eds. H. S. W. Massey, E. W. McDaniel, and B. Bederson), Academic Press, New York (1982). 